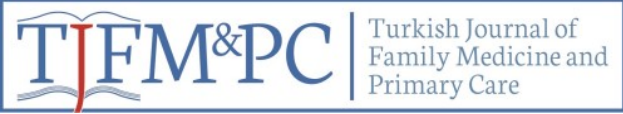

Original Research / Özgün Araştırma

\title{
Histopathological Examination Results and Treatment Modalities of Patients After Pigmented Lesion Excision For Cosmetic Reasons
}

\author{
Estetik Amaçlı Pigmente Lezyon Eksizyonu İçin Başvuran Hastaların Histopatolojik \\ İnceleme Sonuçları ve Tedavi Yönetimi
}

Mehmet Can Şakl ${ }^{* 1}$

\begin{abstract}
Objective: It is very important to recognize the pigmented skin lesions and accompanied malignant skin diseases by physicians working in primary health care facilities. The successful removal of pigmented lesions, especially in the head and neck region, is the general reason for patients admitted to aesthetic surgery clinics. In this study, histopathological diagnoses of the lesions removed for aesthetic purposes are examined retrospectively and treatment management is reviewed. Material and Methods: A total of 85 patients who wanted to remove their pigmented lesions for only aesthetic purposes between November 2018 and November 2019 were included in this study. All patients were operated by the same surgeon. After excisional biopsy, all lesions were examined histopathologically. Results: 129 lesions were removed from 85 patients. 37 (43.5\%) of the patients were male; 48 (56.5\%) were women. The mean age of the patients was 38.9 (14-94 years). The average size of the lesions was $1.15 \mathrm{~cm}^{2}\left(0.3-5.3 \mathrm{~cm}^{2}\right)$. After histopathological examination, 11 different types of pigmented lesion pathology were obtained. Intradermal nevus was the most common pathology result among the lesions (38\%). This was followed by Seborrheic keratosis (24\%) and basal cell carcinoma (22\%), respectively. The head and neck region was the most common location of all lesions that was removed. Incompatibility between the preliminary diagnosis and the histopathological results of the lesions was observed in 5 patients. Conclusion: Patients consult with a wide range of skin lesions in our clinical practice. Although the examination with the naked eye does not always give correct results at the first application of the patient, knowing the $\mathrm{ABCDE}$ criteria is critical at this stage. Considering the patients who refers for only cosmetic purposes are included in our study, we want to emphasize that one fourth of patients are diagnosed with malignant skin cancer and the education of people with skin cancer should be expanded as a public health problem.
\end{abstract}

Key words: Pigmented skin lesions, benign skin tumors, excisional biopsy

\section{ÖZET}

Amaç: Pigmente cilt lezyonlarının birinci basamak sağlık kuruluşlarında çalışan hekimler tarafından tanınması ve eşlik edebilecek malign hastalıklar yönünden araştırılması büyük önem taşımaktadır. Özellikle baş ve boyun yerleşimli olan pigmente lezyonların kozmetik açıdan başarılı bir şekilde çıkarılması hastaların genel başvuru nedeni olmaktadır. Bu çalışmada kliniğimize estetik amaçlarla lezyonlarını aldırmak isteyen hastaların histopatolojik tanıları retrospektif olarak incelenmiş ve tedavi yönetimi irdelenmiştir. Gereç ve Yöntem: Çalışmaya kliniğimize Kasım 2018- Kasım 2019 tarihleri arasında pigmente lezyonlarını sadece estetik amaçlı aldırmak isteyen toplam 85 hasta dahil edildi. Tüm hastalar aynı cerrah tarafından opere edildi. Eksizyon sonrası tüm lezyonlar histopatolojik incelemeye gönderildi. Bulgular: Toplam 85 hastadan 129 lezyon çıkarıldı. Hastaların 37'si (\%43,5) erkek; 48 'i $(\% 56,5)$ kadın idi. Hastaların ortalama yaşı 38,9 (14-94 yaş) idi. Lezyonların ortalama büyüklüğü $1,15 \mathrm{~cm}^{2}\left(0,3-5,3 \mathrm{~cm}^{2}\right)$ idi. Histopatolojik inceleme sonrası 11 değişik tipte pigmente lezyon patolojisi ortaya çıktı. İntradermal nevüs çıkarılan lezyonlar arasında görülen en sık patoloji sonucuydu (\%38). Bunu sırasıyla Seboreik keratoz (\%24) ve bazal hücreli karsinom (\%22) izledi. Baş-boyun bölgesi çıarılan tüm lezyonların en sık yerleşim yeri idi. İlk muayenede konan ön tanıyla lezyonların histopatolojik sonucu arasındaki uyumsuzluk toplam 5 hastada gözlenmiştir. Sonuç: Cilt lezyonları geniş bir yelpazede klinik pratiğimizde karşımıza çıkmaktadır. Hastanın ilk başvurusunda çıplak gözle muayene her zaman doğru sonuç vermese de ABCDE kriterlerinin bilinmesi bu aşamada kritik önemdedir. Çalışmamızda sadece kozmetik amaçlı başvuran hastaların dahil edildiği göz önünde bulundurulduğunda hastaların dörtte birinin malign deri kanseri teşhisi aldığını ve bu bağlamda bir halk sağlığı sorunu olarak deri kanseriyle ile ilgili kişilerin eğitiminin yaygınlaştırılması gerektiğini vurgulamak istiyoruz.

Anahtar Kelimeler: Pigmente cilt lezyonları, benign deri tümörleri, eksiyonel biyopsi

Received date / Geliş tarihi: 24.02.2020, Accepted date / Kabul tarihi: 14.07.2020

${ }^{1}$ Maltepe Üniversitesi Tıp Fakültesi, Plastik,Rekonstrüktif ve Estetik Cerrahi Anabilim Dalı, İstanbul-TÜRKIYE.

*Address for Correspondence / Yazışma Adresi: Mehmet Can Şakı, Maltepe Üniversitesi Tıp Fakültesi, Plastik,Rekonstrüktif ve Estetik Cerrahi Anabilim Dal, İstanbul-TÜRKIYE.

E-mail: drmehmetcansaki@gmail.com

Şakı MC. Estetik Amaçlı Pigmente Lezyon Eksizyonu İçin Başvuran Hastaların Histopatolojik İnceleme Sonuçları ve Tedavi Yönetimi. TJFMPC, 2020;14(3): 474-478.

DOI: $10.21763 /$ tjfmpc.693482 


\section{GíRiș}

Pigmente cilt lezyonlarının birinci basamak sağlık kuruluşlarında çalışan hekimler tarafından tanınması ve eşlik edebilecek malign hastalıklar yönünden araştırılması büyük önem taşımaktadır. Özellikle baş ve boyun yerleşimli olan pigmente lezyonların kozmetik açıdan başarılı bir şekilde çıkarılması hastaların genel başvuru nedeni olmaktadır. Bu nedenle hastaların ilk planda kaygıları estetik olmaktadır ve hastalar lezyonların patolojik incelenmesi ile çok az ilgilenmektedir. Ancak hem epidermal pre-malign lezyonların yıllar içerisinde malign lezyonlara dönüşüm riski; hem de pigmente lezyonların malign lezyonlarla benzer makroskopik özellikler gösterebileceği göz önünde bulundurularak bu lezyonlar ayrıntılı inceleme ve takip gerektirir. $^{1}$

$\mathrm{Bu}$ çalışmada kliniğimize estetik amaçlarla lezyonlarını aldırmak isteyen hastaların histopatolojik tanıları retrospektif olarak incelenmiş ve tedavi yönetimi irdelenmiştir.

\section{GEREÇ ve YÖNTEM}

Bu retrospektif çalışmaya kliniğimize Kasım 2018Kasım 2019 tarihleri arasında pigmente lezyonlarını sadece estetik amaçlı aldırmak isteyen toplam 85 hasta dahil edildi. Daha önce herhangi bir klinikte ön tanı konmuş ya da estetik kaygı dışında lezyonlarını kanser şüphesi için aldırmak isteyen hastalar çalışmaya dahil edilmedi. İlk görüşme esnasında yapılan makroskopik muayeneye ve alınan anamneze göre lezyonların benign ya da malign karakterde olabileceği hastalara söylendi. Hiçbir hastaya dermatoskopik inceleme yapılmadı. Tüm hastalar aydınlatılmış onam formu alındıktan sonra aynı cerrah tarafindan opere edildi. Uygun cerrahi sterilazasyon sağlandıktan sonra lezyonun büyüklüğüne ve rekonstrüksiyon ihtiyacına göre lokal ya da genel anestezi altında tüm lezyonlar güvenli cerrahi sınırlar ile eksize edildi. Eksizyon sonrası tüm lezyonlar histopatolojik incelemeye gönderildi. Tüm hastalar ameliyat sonrası 15 . gün poliklinik kontrolüne çağrılarak gerekli cerrahi bakım ve histopatolojik sonuç takibi yapıldı. Hasta bilgileri hastanemizin bilgisayar kayit sisteminden toplanarak hastaların yaş- cinsiyet dağılımı, ameliyat öncesi ön tanısı; lezyonların büyüklüğü, lokalizasyonu ve histopatolojik tanısı retrospektif olarak incelendi.

\section{BULGULAR}

Toplam 85 hastadan 129 lezyon çıkarıldı. Hastaların 37'si $(\% 43,5)$ erkek; 48'i $(\% 56,5)$ kadın idi. Hastaların ortalama yaşı 38,9 (14-94 yaş) idi. Lezyonların ortalama büyüklüğü $1,15 \mathrm{~cm}^{2}(0,3-5,3$ $\mathrm{cm}^{2}$ ) idi. Histopatolojik inceleme sonrası 11 değişik tipte pigmente lezyon patolojisi ortaya çıktı. Alınan tüm lezyonların patolojik alt tipi, sayısı ve ortalama boyutu ve hastaların bu gruplardaki yaş ortalamaları Tablo-1' de verilmiştir.

\begin{tabular}{|l|c|c|c|c|}
\hline Tablo-1: Alınan tüm lezyonların genel özellikleri & & \\
\hline Patolojik Alt tip & $\begin{array}{c}\text { Alınan } \\
\text { Lezyon } \\
\text { Sayısı }\end{array}$ & $\begin{array}{c}\text { Ortalama Hasta } \\
\text { yaşı }\end{array}$ & Hasta sayısı & $\begin{array}{c}\text { Lezyonlarınortalama } \\
\text { boyutu(cm })^{2}\end{array}$ \\
\hline İntradermal nevüs & 50 & $35 ., 1$ & 29 & 0.73 \\
\hline Seboreik keratoz & 31 & 51.4 & 24 & 1,5 \\
\hline Bazal hücreli karsinom & 29 & 75,2 & 22 & 1.89 \\
\hline Kompound nevüs & 6 & 31,4 & 5 & 1,5 \\
\hline Junctional nevüs & 4 & 73 & 2 & 0.9 \\
\hline Blue nevüs & 3 & 46,5 & 2 & 0.8 \\
\hline Verruka vulgaris & 2 & 44,5 & 2 & 0,9 \\
\hline Kavernöz hemanjioma & 1 & 75 & 1 & 2.5 \\
\hline Ĭğsi hücreli lezyon & 1 & 26 & 1 & 0.5 \\
\hline Malign melanom & 1 & 76 & 1 & 2.2 \\
\hline Bazoskuamözhücrelikarsinom & 1 & 56 & 1 & 0.7 \\
\hline
\end{tabular}


İntradermal nevüs çıkarılan lezyonlar arasında görülen en sık patoloji sonucuydu (\%38). Bunu sırasıyla Seboreik keratoz $(\% 24)$ ve bazal hücreli karsinom (\%22) izledi. Ortalama yaş grubu incelendiğinde en yaşlı hasta grubu bazal hücreli karsinom ve malign melanom grubunda gözlendi.
Aynı hastadan birden fazla lezyonun çıkarıldığı en sık grup intradermal nevüs grubuydu. Ortalama büyüklük olarak en büyük lezyonlar bazal hücreli karsinom grubunda görüldü. Çıkarılan lezyonlar yerleşim yerlerine göre dağılımı Tablo-2'de verilmiştir.

\begin{tabular}{|c|c|c|c|c|}
\hline \multicolumn{3}{|c|}{$\begin{array}{l}\text { Tablo-2: Lezyonların yerleşim yerine göre } \\
\text { dağılımı }\end{array}$} & \multirow[b]{2}{*}{ ÜstEksretmite } & \multirow[b]{2}{*}{$\begin{array}{l}\text { Alt } \\
\text { ekstermite }\end{array}$} \\
\hline Patolojik Tip & $\begin{array}{l}\text { Baş- } \\
\text { boyun }\end{array}$ & Gövde & & \\
\hline İntradermal nevüs & 36 & 11 & 2 & 1 \\
\hline Seboreik keratoz & 20 & 7 & 1 & 3 \\
\hline Bazal hücreli karsinom & 25 & 3 & 1 & 0 \\
\hline Kompound nevüs & 0 & 4 & 1 & 1 \\
\hline Junctional nevüs & 1 & 1 & 0 & 2 \\
\hline Blue nevüs & 2 & 0 & 1 & 0 \\
\hline Verruka vulgaris & 1 & 0 & 1 & 0 \\
\hline Kavernöz hemanjioma & 0 & 1 & 0 & 0 \\
\hline İğsi hücreli lezyon & 1 & 0 & 0 & 0 \\
\hline Malign melanom & 1 & 0 & 0 & 0 \\
\hline Bazoskuamözhücrelikarsinom & 1 & 0 & 0 & 0 \\
\hline
\end{tabular}

Baş-boyun bölgesi çıkarılan tüm lezyonların en sık yerleşim yeridir (\%62). Alt gruplar incelendiğinde çıkarılan intradermal nevüslerin \%72'si, seboreik keratozların \%64'ü; bazal hücreli karsinomların \%86's1 baş-boyun bölgesinde yerleşiktir. Lezyonların tedavi şekline göre dağılımı Tablo3'de verilmiştir.

\begin{tabular}{|c|c|c|c|}
\hline \multicolumn{3}{|c|}{ Tablo-3: Lezyonların tedavi şekline göre dağılımı } & \\
\hline Patoloji Tipi & $\begin{array}{l}\text { Primer } \\
\text { Sütür }\end{array}$ & Sekonder İyileşme & $\begin{array}{l}\text { Bölgesel Flep-Greft ile } \\
\text { rekonstrüksiyon }\end{array}$ \\
\hline İntradermal nevüs & 49 & 1 (burunucu) & 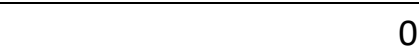 \\
\hline Seboreik keratoz & 29 & $\begin{array}{r}2 \text { (burunucu, medial } \\
\text { kantus) }\end{array}$ & 0 \\
\hline Bazal hücreli karsinom & 20 & $\begin{array}{r}2 \text { (burunucu, medial } \\
\text { kantus) }\end{array}$ & 7 \\
\hline Kompound nevüs & 6 & 0 & 0 \\
\hline Junctional nevüs & 4 & 0 & 0 \\
\hline Blue nevüs & 3 & 0 & 0 \\
\hline Verruka vulgaris & 2 & 0 & 0 \\
\hline Kavernöz hemanjioma & 1 & 0 & 0 \\
\hline İ̆si hücreli lezyon & 1 & 0 & 0 \\
\hline Malign melanom & 0 & 0 & 1 \\
\hline Bazoskuamözhücrelikarsinom & 1 & 0 & 0 \\
\hline
\end{tabular}


İlk muayenede konan ön tanıyla lezyonların histopatolojik sonucu arasındaki uyumsuzluk toplam 5 hastada gözlenmiştir. Bu hastalar Tablo4'de özetlenmiştir.

\begin{tabular}{|l|c|l|l|l|}
\hline \multicolumn{5}{|c|}{ Tablo-4: Ön tanı ve histoplatoloji uyumsuzlukları } \\
\hline Ön tanı & Yaş & Lezyon yerleşim yeri & Patoloji Sonucu & Hekimin Notu \\
\hline Malign Şüpheli & 76 & Burun Ucu & Intradermal Nevüs & Makroskopik olarak ileri pigmente, yaş ve güneşe maruziyet risk faktörü \\
\hline Malign Şüpheli & 76 & Burun Ucu & Seboreik Keratoz & Makroskopik olarak ileri pigmente, yaş ve güneşe maruziyet risk faktörü \\
\hline Malign Şüpheli & 45 & Skalp & Seboreik Keratoz & Makroskopik olarak ileri pigmente, alopesi ve güneşe maruziyet risk faktörü \\
\hline Benign & 68 & Yanak & Bazal hücreli Karsinom & ABCDE kurallarına göre benign karakterli, boyutu küçük düşük pigmente \\
\hline Benign & 56 & Burun-Yanak birleşkesi Bazoskuamöz hücreli Karsinon ABCDE kurallarına göre benign karakterli, boyutu küçük düşük pigmente \\
\hline & & & & \\
\hline
\end{tabular}

\section{TARTIŞMA}

$\mathrm{Bu}$ retrospektif çalışmamızda kliniğimize kozmetik amaçlı pigmente lezyonlarını aldırmak isteyen hastalar irdelenmiştir. Çıkarılan lezyonlar histopatolojik olarak incelendiğinde hastalarda en sık intradermal nevüs daha sonra sirasıyla seboreik keratoz ve bazal hücreli karsinom teşhisi konmuştur. Bir hastada bazoskuamöz hücreli karsinom ve bir hastada malign melanom teşhisi konmuştur. Hastalar en çok baş-boyun bölgesindeki lezyonların alınmasını istemişlerdir.

Melanositik nevüsler doğumla birlikte görülebilirler, ancak büyük çoğunluğu çocukluk ve erken erişkin dönemde edinsel olarak ortaya çıkar. Oluşumunda hem genetik faktörler hem de çevresel faktörler (güneşe maruziyet) önemli rol oynar. ${ }^{2}$ Melanositik nevüsler benign melanosit proliferasyonları olup üç gruba ayrılmaktadır. Dermoepidermal bileşkede bulunanlar junctional, dermisde bulunanlar intradermal, hem junctional hem de intradermal özelliklerin ikisini birden içeriyorsa birleşik (kompound) nevüs olarak isimlendirlirler. Klinik olarak en s1k güneşe maruz kalan alanlarda görülür, asemptomatiktir ve çoğunlukla benign olarak kabul edilirler. ${ }^{3}$ Ancak nevüs, seboreik keratoz gibi derinin benign lezyonlarını çıplak gözle malign melanomdan ayırt etmek klinik beceri ister. Bu aşamada ayırıcı tanıda ABCDE kriterleri (Asymmetry, Border irregularity, Color irregularity, Diameter $>6 \mathrm{~mm}$, Evolution) iyi bir muayene yöntemidir. Hekim çılak gözle bu muayene sonrası şüpheli lezyon düşünüyorsa hastayı ya dermatoskopik incelemeye ya da biyopsiye yönlendirmelidir. ${ }^{4}$

Seboreik keratozlar epidermiste görülen klinik oalrak sınırları belirgin plak ya da papüller şeklinde ayırt edilebilen lezyonlardır. Genelde kozmetik sebeplerle hastalar alınmasını isterler. Oluşumunda genetik faktörlerle birlikte güneşe maruziyet iki önemli faktördür. Ayırıcı tanıda özellikle bazal hücreli karsinom ve malign melanomdan ayrımı yapılmalıdır. ${ }^{5,6}$

Bazal hücreli karsinom insanlarda görülen en sık malign deri tümörüdür. $\mathrm{Bu}$ tümörler \%60-80 oranında baş-boyun bölgesinde yerleşiktir. Lokal agresif seyri dolasıyla özellikle burun, göz etrafı ve yanaklarda yerleşmiş olan tümörlerin eksizyonu çoğunlukla rekonstrüksiyon ihtiyacı doğurmaktadır. Uzun yıllar asemptomatik seyredebilir. Oluşumunda güneşe maruziyet önemli rol oynamaktadir. $^{7}$

Malign melanom melanosit hücrelerinden köken alan morbidetesi ve mortalitesi yüksek deri tümörüdür. İnsidansı giderek artış göstermektedir. $\mathrm{Bu}$ yönüyle malign melanom bir halk sağlığ1 sorunu haline gelmektedir. Oluşumunda iyi bilinen risk faktörlerinden bir tanesi güneşe maruziyettir. ${ }^{8}$

Çalışmamızda elde edilen bulgular incelendiğinde; lezyonların histopatolojik alt tiplerinin siklık oranları; hasta yaş ortalamaları ve histopatolojik alt tip korelasyonu; lezyonların yerleşim yeri sıklığı literatürde mevcut benzer çalışmalarla benzerlik göstermektedir.9-13 Har-Shai et al. deri lezyonlarında klinik tanının sensivitesini malign lezyonlarda \%91,3, pre-malign lezyonlarda \%42,3 ve benign lezyonlarda \%85,9 olarak göstermişlerdir. ${ }^{14}$ Hallock ve Lutz, 2000 deri lezyonunun prospektif analizin içeren çalışmalarında, benign ya da malign özellikte olabilecek lezyonların doğru klinik muayene ile $\%$ oranında teşhis edilebileceğini belirtmişlerdir. ${ }^{15}$

Çalışmamızda üç hasta klinik muayenede ön tanı olarak malign olarak değerlendirilmiş ancak histopatolojik sonuçları benign olarak raporlanmıştır. $\mathrm{Bu}$ hastalarda ileri yaş, güneşe sık maruziyet ve anamnezde elde edilen lezyondaki renk ve boyut değişikliği bu ön tanıyı koymamıza neden olmuştur. Çalışmamızda iki hasta ise ön tanıda benign olarak değerlendirilmiş ancak 
histopatoloji sonucu malign gelmiştir. $\mathrm{Bu}$ hastalarda lezyonunun boyutunun küçük olması ve anamnezde hastaların lezyonlarda hiçbir değişiklik olmadığını belirtmesi bu ön tanıları koymamıza neden olmuştur. Çalışmamızda 7 hastaya bazal hücreli karsinom nedeniyle bölgesel flep ya da greft ile rekonstrüksiyon uygulanmıştır. $\mathrm{Bu}$ hastalardan bir tanesi hem kozmetik sonuçtan hem de tümörün erken tanınıp alınmamasından dolayı memnuniyetsizliğini belirtmiştir. $\mathrm{Bu}$ çalışmayla hem birinci basamak sağlık kuruluşlarında çalışan hekimlere hem de ikinci üçüncü basamak sağlık kuruluşlarında çalışan hekimlere deri tümörleriyle ilgili klinik muayenenin önemini vurgulamak istiyoruz. Çalışmamızda sadece kozmetik amaçlı başvuran hastaların dahil edildiği göz önünde bulundurulduğunda hastaların dörtte birinin malign deri kanseri teşhisi aldığını ve bu bağlamda bir halk sağlığı sorunu olarak deri kanseriyle ile ilgili kişilerin eğitiminin yaygınlaştırılması gerektiğini vurgulamak istiyoruz.

\section{SONUÇ}

Cilt lezyonları geniş bir yelpazede klinik pratiğimizde karşımıza çıkmaktadır. Hastanın ilk başvurusunda çıplak gözle muayene her zaman doğru sonuç vermese de ABCDE kriterlerinin bilinmesi bu aşamada kritik önemdedir. Cilt lezyonlarının teşhisi ve sonraki tedavi yönlendirmesi tamamen iyi yapılandırılmış anamneze, klinik görünüme ve eşlik eden hastanın belirttiği semptomlara dayalıdır. Böylece ham halkın deri kanseriyle ile ilgili bilinçlendirilmesi hem de hekimlerin deri lezyonları muayenelerinde tecrübe kazanmaları yanlış pozitif ve yanlış negatif ön tanıları engelleyecektir.

\section{KAYNAKLAR}

1. Tanriverdi MH, Turan E. Birinci Basamakta Epidermal Prekanseröz Lezyonlara Yaklaşım. Konuralp Tip Dergisi 2010;2(1):53-56

2. Trost JG, Applebaum DS, Orengo I. Common Adult Skin and Soft Tissue Lesions. Semin Plast Surg 2016; 30:98-107

3. Yavuz GO, Yavuz IH. Melanositik Nevüsler. Van Tip Dergisi 2014; 21(4):259-268

4. Usatine RP, Smith MA, Mayeaux EJ Jr, Chumley HS. The Color Atlas and Synopsis of Familiy Medicine, 3e. McGraw Hill Education. 2019:168; 1038-45

5. Lee EH, Nehal KS, Disa JJ. Benign and premalignant skin lesions. Plast Reconstr Surg. 2010;125(5):188e-198e

6. Hafner C, Vogt T.Seborrheic keratosis. J Dtsch Dermatol Ges. 2008; 6:664-677

7. Frerich, B., Prall, F. Basalzellkarzinom der Gesichts- und Kopfhaut. MKG-Chirurg.2018; $11,49-63$
8. Agadayı E, Alsancak AD, Ustunal D et.al. Aile Hekimliği Polikliniğine Başvuran Hastalarda Malign Melanom Risk Faktörlerinin Değerlendirlmesi ve Güneşten Korunma Hakkında Tutumları. Konuralp Tip Dergisi. 2017;9(3):1-6

9. Ersen, B., Akin, S., Saki, M.C. et al. Clinical and histopathological analysis of 152 pigmented skin lesion excisions apart from melanocytic nevus due to cosmetic reasons. Eur J Plast Surg. 2015; 38, 273-78 (2015)

10. Ersen, B., Akin, S., Sahin, A. et al. Clinical and histopathological analysis of 790 naevi excised from 509 patients due to cosmetic reasons. Eur J Plast Surg. 2015;38, 133-138

11. Nazer MR, Hajihoseini M, Hatkehlouei MB,et al. Prevelance of pigmented Nevus in Sari, North of Iran. A retrospective Study on 719 Patients. Int J Sci Stud. 2017;5(7):217-20

12. Rivers JK, MacLennan R, Kelly JW, et al. The eastern Australian childhood nevus study: prevalence of atypical nevi, congenital nevus-like nevi, and other pigmented lesions. Journal of the American Academy of Dermatology 1995; 32(6):957-63.

13. Gallagher RP, Rivers JK, Yang CP et al. Melanocytic nevus density in Asian, IndoPakistani, and white children: the Vancouver Mole Study. Journal of the American Academy of Dermatology 1991; 25(3):507-12.

14. Har-Shai Y, Hai N, Taran A, et al. Sensitivity and positive predictive values of presurgical clinical diagnosis of excised benign and malignant skin tumors: a prospective study of 835 lesions in 778 patients. Plast Reconstr Surg. 2001;108(7):19821989.

15. Hallock GG, Lutz DA. Prospective study of the accuracy of the surgeon's diagnosis in 2000 excised skin tumors. Plast Reconstr Surg. 1998;101(5):1255-1261. 